\title{
Dense Medium Machine Processing Method for Palm Kernel/ Shell Separation
}

\section{${ }^{1}$ IBRAHIM, OA; ${ }^{2} \mathrm{UCHE}, \mathrm{C} ;{ }^{3} \mathrm{MAHDI}, \mathrm{M} ;{ }^{2} \mathrm{MICHAEL}, \mathrm{CA} ;{ }^{4}$ SYLVESTER, G}

\author{
${ }^{1}$ Hydraulic Equipment Development Institute, NASENI, FMST, Kano. \\ ${ }^{2}$ National Board for Technology Incubation, FMST, Abuja, \\ ${ }^{3}$ Department of Mechanical Engineering, Faculty of Engineering, Bayero University, Kano \\ ${ }^{4}$ National Research Institute for Chemical Technology, FMST, Zaria \\ Corresponding Author: makwayo@gmail.com
}

\begin{abstract}
A machine processing method for the separation of cracked palm kernel from the shells using dense medium is presented. Cracked palm kernel is a mixture of kernels, broken shells, dusts and other impurities. In order to produce quality palm kernel oil, clean palm kernel nuts must be used, therefore the need for the separation of the palm kernel nuts from the shells. Several methods are used in the separation. The handpicking method yields good quality kernels but the method is slow, laborious and unsuitable for large scale productions. Salt solution method is unsuitable because of acidity of concentrated solution of salt used which affects the palm kernel as well as the quality of the oil produced. The clay suspension method is time consuming, laborious and cumbersome. The limitations of the above-stated methods of separation gave rise to the need for alternative methods of separation. A machine processing method using dense medium, a separator, a shell collector and a kernel collector was proposed. A machine was developed which produced kernels that contain $6.5 \%$ moisture content, $51 \%$ fat, $8.9 \%$ protein, $7 \%$ free fatty acid and $1.9 \%$ ash content. The kernels from the machine separation method were compared with the kernels produced by the other methods. The results revealed that the kernels obtained by hand picking method contains $7 \%$ moisture content, $52 \%$ fat, $9 \%$ protein, $7 \%$ free fatty acid and $2 \%$ ash content. The ones obtained using salt solution bath method contain $6 \%$ moisture content, $45 \%$ fat, $8 \%$ protein, $4.5 \%$ free fatty acid and $1.7 \%$ ash content. The ones obtained using conventional clay bath method contain $8 \%$ moisture content, $48 \%$ fat, $8.5 \%$ protein, $5.5 \%$ free fatty acid and $1.8 \%$ ash content. From the results obtained, the dense medium separation and clay suspension methods provide a better and cleaner means of palm kernel nut and shell separation because of the low moisture content and high fat, protein and ash contents among the methods of separation used.
\end{abstract}

DOI: https://dx.doi.org/10.4314/jasem.v21i7.20

Copyright @ 2017 Ibrahim et al. This is an open access article distributed under the Creative Commons Attribution Non-Commercial License (CC-BY-NC), which permits unrestricted use, distribution, and reproduction in any medium, provided the original work is properly cited.

Received 31 September 2017, received in revised form 18 October 2017, accepted 29 November 2017.

Keywords: Palm Kernel, Shell, Separation, Machine Processing Method, Dense Medium.

Nigeria is one of the world largest exporters of palm kernel products in early sixties, providing about 400,000 metric tons amounting to $65 \%$ of the world trade. Nigeria export of palm kernel nut reduced drastically in the seventies, from 65 to $15 \%$ because of the oil boom. Based on high dependent of many companies like soap, vegetable oil and body cream industries on palm kernel products both within and outside the country, efficient palm kernel processing is not only necessary but also important to revitalize the production of palm kernel in order to meet up with ever increasing industrial demand of palm kernel products (Oke, 2007). Palm kernel is the raw material for the extraction of palm kernel oil. It is obtained from palm nuts which are cracked after removing the oil rich mesocarp. Palm kernel oil is a white to yellowish oil obtained from the palm kernels. Palm kernel oil is different from palm oil, which is obtained from the flesh of the palm fruit (Gbasouzor et al., 2012). Palm products (Palm oil and palm kernel) accounted for about $51.2 \%$ of the total Nigeria's domestic export between 1906 and 1913. It earned the nation about 22\% of its foreign exchange up to the beginning of the
Nigerian civil war. Nigeria's domestic palm oil production as at 1986 was estimated to be 760000 metric tons. The palm kernel cake, which is a major ingredient in livestock feed manufacture is a byproduct of palm kernel processing. Palm kernel oil which is used very extensively in bakery and in making ice creams, detergents and pomades is also a byproduct of palm kernel processing. The oil and cake are obtained in a process of crushing palm kernels (Onoh and Onoh, 2012). A study by Ozor Godwin (2012) for XYZ Agroindustries Ltd showed that palm kernel expelling business is a raw material processing business. This is because the product is still a raw material for refineries that use it to produce edible vegetable oil. The basic raw material in this palm kernel processing industry is palm kernel and the finished products are Palm Kernel Oil (PKO), Palm Kernel Cake (PKC) and Palm Kernel Sludge (PKS). The major threat to the businesses of palm kernel oil production is the scarcity of palm kernel due to the inefficiency of the methods used for palm kernel separation from the shells (Ozor, 2012). The two major dense mediums methods used for palm kernel separation from the shells are the salt solution and clay 
suspension methods. The salt method uses salt solution or brine in a bath while the clay method employs a clay suspension. When the cracked mixture is admitted into the bath, the denser shells sink to the bottom while the less dense kernels float. A plastic container or aluminum pot is then used for the separation. The tank or pot is filled with water and the salt or clay is added in the right proportion so that the required density of the suspension is obtained. The cracked palm kernel mixture is poured into the tank. The difference in densities makes the shells to sink and the kernels to float. The kernels are then skimmed off the surface of the suspension while the shells are evacuated. Drying of the shells and nuts is done under the sun. One of the problems associated with the clay method is that of maintaining the solution within the appropriate density range during the separation process. Another problem that may likely arise from the clay method is the disposal of water after the process (Okoronkwo et al., 2013). Oke, (2007) states that the clay method consumes a lot of time in washing and drying the kernel and makes the kernel susceptible to infection of fungi thereby reduces the quality of oil and cake that can be produced. The separation process the clay method consumes time and the time of contact between the clay, water and kernels is usually long making it possible of yield poor quality kernels as a result of clay and water contamination of the kernels. The salt solution methods also has its shortcomings because the brine concentration penetrates into the kernel and react with the kernels' constituents yielding poor quality kernel. Chemically, clays are hydrous aluminum silicates, ordinarily containing impurities, for example potassium, sodium, calcium, magnesium, or iron, in small amounts, and are characterized by sheet silicate structures of composite layers stacked along the c-axis. (Akhirevbulu et al., 2010). Thus, though clay method is preferred to salt method, it is still very pertinent to avoid long contact of kernels and the clay suspension so as to avoid reactions between elements of the clay constituents and palm kernel in order to achieve better quality oil and cake from the kernels. In this paper, a machine processing method for separation of the kernels and shells is proposed. The objectives are to design a machine that will assist in reducing the hardship of the hand picking, salt and clay separation methods as well as propose a means of reducing the kernel, clay and water contact period used in the clay method of separation, thereby producing clean palm kernels that will be used to produce good quality palm kernel oil and cake.

\section{MATERIALS AND METHOD}

Description of the machine: The dense medium processing machine (Figure 1) comprises of a dense medium tank and a water tank (Figure 2). There are also three other containers the separator, the shell collector and the kernel collector (Figure 3). During operation of the machine, the dense medium inside the shell collector and kernel collector are discharged into the media tank. The separator, the shell collector and the kernel collector are assembled on the machine frame so that they can discharge their content using two water pumps. One of the pumps circulates the dense medium while the other circulates water. One of the pumps takes the dense medium from the dense medium tank and pumps it into the separator. Two ports at the top of the dense medium tank are used for returning discharges from the shell collector and palm kernel collector. At the beginning of the machine operation, the separation chamber is empty. Palm Kernel/Shell mixture is poured into the chamber. The dense medium pump then pumps the medium into the chamber. The flow is cut off before it reaches the brim of the chamber. A little time is allowed for swirling fluid motion to stop. The kernels float while the shells sink. By overflow or by the tilting of the separator, the kernels are discharged into the kernel collector. When the bottom gate valve of the separator is opened, the shells and fluid are discharged into the shell collector. Water is then pumped into the kernel collector to wash the kernels before drying. As the shells and kernels enter the collectors respectively, the dense medium returns to the media tank through one of the upper ports. The return ports have filters to filter out debris from the mixture.

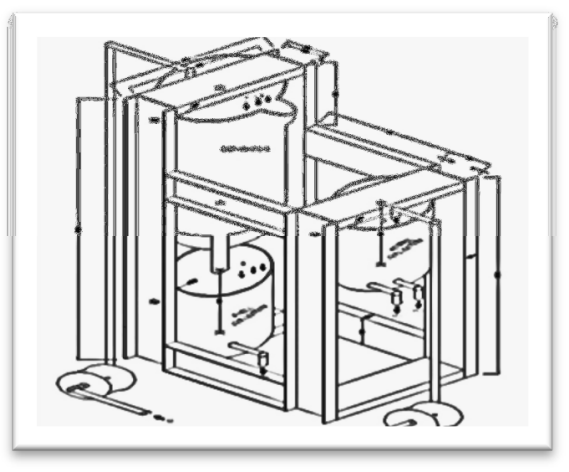

Fig 1: The Dense Medium Processing Machine

Sizing of the tanks: The types of tanks used in this work are two rectangular tanks (for dense medium and water) and three cylindrical (circular) tanks (for the separator, shell collector and palm kernel collector). Storage reservoirs and overhead tank are used to store water, liquid petroleum, petroleum products and similar liquids The basic principles used in the design of tanks for the storage of oil or water is covered in BS 2654 (British Standard Institution, 2003) and API 650 (American Petroleum Industry, 2012). 
Design Pressure: Tanks designed for storage work at relatively small positive internal pressures of up to 56 mbar or $5.6 \mathrm{kN} / \mathrm{m}^{2}$ according to BS 2654 .

Tank material: Carbon Steel is considered as first choice, due to its lower cost, ready availability and good fabrication and testing properties. The tanks in this work were manufactured from plain carbon steel plate (traditionally referred to as mild steel).

Tank Shell Design: The tank shells were designed accordance to the API 650 (2007). Based on the tank size of $750 \mathrm{~mm}$ diameter, 1 -Foot method was used. The formula for the minimum required tank plate thickness according to 1-Foot method is: (API 650, 2007):

$t_{d}=\frac{4.9 D(H-0.3) G}{S_{d}}+C A$

Where, $t_{d}=$ Design plate shell thickness $(\mathrm{mm}), D=$ Nominal diameter of tank $(\mathrm{m}), \mathrm{H}=$ Design liquid level (m), $G=$ Specific gravity of the liquid stored, $S_{d}=$ Allowable stress for the tank material $(\mathrm{MPa}), C A=$ Corrosion Allowance.

\section{Design Data:}

- Tank Material: Low Carbon steel AISI 1018, Modulus of elasticity $(\mathrm{E})=205 \mathrm{GPa}$, Yield Strength $\left(S_{d}\right)=307 \mathrm{MPa}$ (taken as the allowable stress), Poisson ratio $=0.3$, Density of steel $(\rho)=$ $7850 \mathrm{~kg} / \mathrm{m}^{2}$ (Cambridge, 2003)

- Tank Dimensions: For rectangular tanks (dense medium and water tanks): Length $(\mathrm{L})=800 \mathrm{~mm}$, Width $(\mathrm{w})=800 \mathrm{~mm}$ and Height $(\mathrm{H})=800 \mathrm{~mm}$. For the circular tanks (separator tank): Diameter (D1) = $750 \mathrm{~mm}$ and Height $(\mathrm{H} 1)=1100 \mathrm{~mm}$. For the circular tanks (shell collector and kernel collector tanks): Diameter $(\mathrm{D} 2)=600 \mathrm{~mm}$ and Height $(\mathrm{H} 2)=$ $600 \mathrm{~mm}$.

- Type of liquid: Water was considered for the design. Specific Gravity $(\mathrm{G})=1$ and Density $=$ $1000 \mathrm{~kg} / \mathrm{m}^{3}$

- Corrosion Allowance (CA). $C A=3 \mathrm{~mm}$ was selected for steel exposed to corrosive waters.

- Nominal Diameter of Tank (D). The nominal diameter of tank was taken as the diagonal of the rectangular tanks which was calculated as $1131.37 \mathrm{~mm}$ or $\mathrm{D}=1.13 \mathrm{~m}$
- Design Liquid level $(H)$. The design liquid level was taken as $90 \%$ of the rectangular tank height, i.e. $90 \%$ of $800 \mathrm{~mm}=720 \mathrm{~mm}$ or $0.72 \mathrm{~m}$

Using the design data and equation 1, the plate shell thickness was calculated as:

$t_{d}=\frac{4.9 \times 1.13(0.72-0.3) 1}{370}+3=0.00629+3=3.0063 \mathrm{~mm} \approx 3 \mathrm{~mm}$

Using the mild steel plate thickness chart (The Engineering ToolBox, 2016), 4mm thick plate was selected. This plate thickness was used in the fabrication of the shells of all the tanks used in the machine.

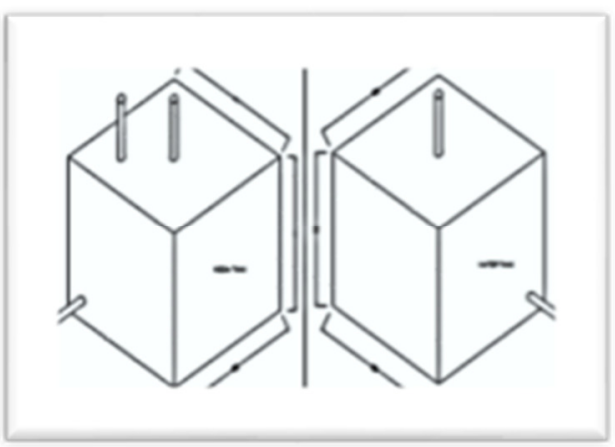

Fig 2: Dense Medium Tank and Water Tank

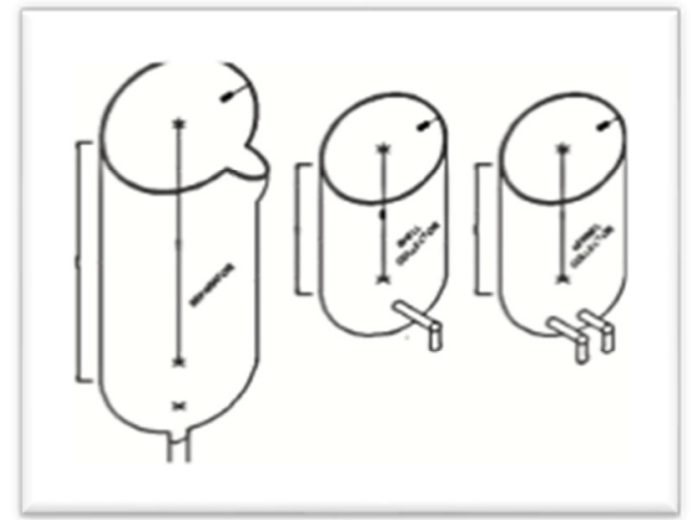

Fig 3: The Separator, Shell Collector and Palm Kernel Collector

\section{Selection of pumps}

In this design, the pumping static head was taken as $2.5 \mathrm{~m}$ based on the overall height of the machine while the mass flow rate is taken as $0.63 \mathrm{~L} / \mathrm{s}(37.8 \mathrm{~L} / \mathrm{min})$. Based on design factors such as feed type, cost implications, environmental considerations, operating conditions of the plant and its various processes, etc. a centrifugal pump was selected based on its high efficiency, ease of maintenance and uniformity of output torque. The steps to follow to select a type of centrifugal pump are: 
Determination of the flow rate: To select a centrifugal pump, the flow rate is determined first. A flow rate of $0.63 \mathrm{~L} / \mathrm{s}$ to fill the tanks in a reasonable amount of time was selected. (Jacques, 2005)

Determination of the static head: This is the measurements of the height between the suction tank fluid surface and the discharge pipe end height or the discharge tank fluid surface elevation. The static head was taken as $2.5 \mathrm{~m}$ based on the overall height of the machine.

Determination of the friction head: The friction head depends on the flow rate, the pipe size and the pipe length. Using Cameron Hydraulic data book, for a flow rate of $0.63 \mathrm{~L} / \mathrm{s}$ and pipe of 1 inch $(25.4 \mathrm{~mm})$ diameter, the friction loss is $0.0861 \mathrm{ft}$ per $\mathrm{ft}$ of pipe or 0.026 meter per meter of pipe (Westaway and Loomis, 1984). In this case, for the distance of $2.5 \mathrm{~m}$, the friction loss in meter will be $2.5 \times 0.026=0.065 \mathrm{~m}$. There is also some friction loss in the pipe fittings, let's assume an estimate of $30 \%$ of the pipe friction head loss, the fittings friction head loss is $0.3 \times 0.065=0.0195 \mathrm{~m}$. Therefore, the total friction loss is $0.065+0.0195=0.0845 \mathrm{~m}$

Calculation of the total head: The total head is the sum of the static head and the friction head, i.e. $2.5+0.0845$ $=2.5845 \mathrm{~m}=2.6 \mathrm{~m}$

Selected pumps: The pump was selected based on the pump manufacturer's catalogue information using the total head and flow required as well as suitability to the application. The pumping head is $2.5 \mathrm{~m}$ and flow rate $0.63 \mathrm{~L} / \mathrm{s}(37.8 \mathrm{~L} / \mathrm{min})$, based on other design factors such as feed type and operating conditions of the plant, two Pedrollo centrifugal pumps, CPm100 model with the following characteristics volumetric flow rate of up to $60 \mathrm{~L} / \mathrm{min}$, power of up to $0.25 \mathrm{~kW}$, dynamic head of up to $15 \mathrm{~m}$ and pipe size of 1 inch by 1 inch were selected (Pedrollo, 2017).

\section{Fabrication and assembly of machine}

The assembly of the machine was performed using various joining methods. The tank shells, top and bottom covers were fabricated from low carbon (mild) steel using shielded metal arc welding process. The pumps, pipes and other accessories were selected and assembled to form the machine.

\section{Performance evaluation of machine}

After fabricating the machine it was evaluated by comparing its performance with three other methods of separation, namely: hand picking method, manual salt solution method and manual clay suspension method. Samples for the tests were prepared by collecting crack palm nuts yielding palm kernel-shell mixture with sand and dirt particles. A $200 \mu \mathrm{m}$ mesh was used to sieve out sand and dirt particles. The mixtures were then separated using the different separation methods. The results of the analysis of the chemical composition of the samples separated by different methods are presented in Table 1.

Hand Picking Method. A weighing spring balance of range $10-100 \mathrm{~kg}$ and two 100 litres plastic containers were used. One bag of cracked palm nuts comprising of palm kernels, shells and broken kernels weighing $58 \mathrm{~kg}$ was assigned to a worker to separate by hand picking.

Manual Salt Solution Method: A weighing spring balance of range $10-100 \mathrm{~kg}$, a hydrometer, two 100 litre plastic containers and 90 litres salt solution were used. The kernels and shells were poured into the salt solution and stirred manually. The shells sank to the bottom of the bowl while the kernels floated. The floated kernels were skimmed off and washed in a bowl containing water. The collected kernels were dried in the sun.

Manual Clay Suspension Method: A weighing spring balance of range $10-100 \mathrm{~kg}$, a hydrometer, two 100 litre plastic containers and 90 litres clay suspension were used. The kernels and shells were poured into the clay bath and stirred manually. As the shells sank to the bottom of the bowl, the operator continuously stirred the suspension while skimming-off the kernels which floated. The collected kernels were washed in a bowl containing water. Thereafter the collected kernels were dried under the sun.

Processing Machine Method: A separating cylinder, kernel and shell collectors, spring balance and a hydrometer were used. Cracked palm kernel-shell mixtures weighing $60 \mathrm{~kg}$ were poured into the separating tank. The separating tank was then tilted to evacuate the floating kernels into the kernel collector where they were washed and transferred for drying.

\section{RESULT AND DISCUSSION}

It can be seen from Table 1 that the palm kernel samples separated by hand picking contains $7 \%$ moisture content, $52 \%$ fat, $9 \%$ protein, $7 \%$ FFA and $2 \%$ ash content. Sample separated using salt solution contains $6 \%$ moisture content, $45 \%$ fat, $8 \%$ protein, $4.5 \%$ FFA and $1.7 \%$ ash content. Sample separated using clay suspension contains $8 \%$ moisture content, $48 \%$ fat, $8.5 \%$ protein, $5.5 \%$ FFA and $1.8 \%$ ash content. Sample separated using the processing machine method contains $6.5 \%$ moisture content, $51 \%$ fat, $8.9 \%$ protein, $7 \%$ FFA and $1.9 \%$ ash content. From 
the result obtained, the process machine method and clay suspension method showed a better and cleaner means of palm kernel shell separation than the other methods because the moisture contents of the kernel in the two methods after separation are the lowest while the fat, protein and ash contents are the highest among the methods of separation used.

Table 1: Properties of Palm Kernel Samples separated by different methods

\begin{tabular}{cllccccc}
\multicolumn{2}{c}{ Table 1: Properties of Palm Kernel Samples separated by different methods } \\
\hline SR/N. & Separation Method & $\begin{array}{l}\text { Samples } \\
\text { Identity }\end{array}$ & Moisture (\%) & Fat (\%) & Protein (\%) & $\begin{array}{c}\text { Free Fatty Acid } \\
\text { (FFA) }(\%)\end{array}$ & Ash (\%) \\
\hline 1. & Hand Picking & Kernel & & & & 7 & 2 \\
HP & 7 & 52 & 9 & 8 & 4.5 & 1.7 \\
2. & Salt Solution & Kernel $_{\mathrm{SALT}}$ & 6 & 45 & 8.5 & 5.5 & 1.8 \\
4. & Clay Suspension & Kernel $_{\mathrm{CLAY}}$ & 8 & 48 & 7.9 & 7 & 1.9 \\
\hline
\end{tabular}

Conclusion: A dense medium process machine was developed for the separation of cracked palm kernel nuts from the shells. After fabricating the machine, the properties of kernels separated using the machine process method were determined and compared with hand picking method, manual salt solution method and manual clay suspension method. Based on the result obtained, the dense medium process machine method is an alternative method of kernel separation as compared to manual hand picking and salt solution methods.

\section{REFERENCES}

Akhirevbulu O.E., Amadasun C.V.O., Ogunbajo M.I. And Ujuanbi O (2010). The Geology and Mineralogy of Clay Occurrences around Kutigi Central Bida Basin, Nigeria. Ethiopian Journal of Environmental Studies and Management Vol.3 No.3: 49-56.

American Petroleum Institute, (2012). API 650 Welded Steel Tanks for Oil Storage, 12th Edition, American Petroleum Institute. 1220 L Street, NW, Washington, D.C.

British Standards Institution, (2003). BS 2654 Specification for Manufacture of Vertical Steel Welded Storage Tanks with Butt-welded Shells for the Petroleum Industry, British Standards Institution, London.

Cambridge (2003). Materials Data Book, Cambridge University Engineering Department.

Gbasouzor A. I., Okeke A. C and Chima L. O. (2012). A Plant Design for Mechanical Extraction of Nmanu Aki (Palm Kernel Oil) Using Complete Pretreatment Process. Proceedings of the World Congress on Engineering and Computer Science, Vol II, October 24-26, 2012, San Francisco, USA.

Healy B (1992). Surface Modified Clays: An Innovative Technology for Groundwater
Remediation. Published by Colloid environmental Technologies Company, Arlington Heights, Illinois.

Jacques Chaurette (2005). Centrifugal pump systems. Fluid Design Inc. Montreal, Canada. http://www.etivc.org/techpage_files/pump\%20tu torial.pdf. Accessed February 2017.

Oke P. K (2007). Development and Performance Evaluation of Indigenous Palm kernel Dual Processing Machine. Journal of Engineering and Applied Sciences 2 (4): 701-702.

Okoronkwo C. A., Ngozi-Olehi L. C. And Nwufo O. C (2013). The Adaptation of Clay-Bath and Hydro-cyclones in Palm Nut Cracked-Mixture Separation to Small-Scale Oil Palm Processing Industry. International Journal of modern Engineering Research, Vol. 3: 2023-2024.

Onoh P. A. And Onoh C. A. (2012). Adoption of Improved Oil Palm Production Technology among Farmers in Aboh Mbaise Local Government Area of Imo State. International Journal of Agricultural and Rural Development, Volume 15 (2): 198-203.

Ozor G. (2012). Palm Kernel Oil Extracting Business Plan.

http://www.academia.edu/25528566/the_palm_k ernel_oil_extracting_bussiness_plan. Accessed July $201 \overline{6}$.

Pedrollo (2016), Pedrollo Centrifugal Pumps. Accessed November 2016.

The Engineering ToolBox, (2016). Steel Plates - Size and Weight.

https://www.engineeringtoolbox.com/steelplates-weight-d_1561.html. Accessed November 2016

Westaway C R and Loomis A.W. (1984), Cameron Hydraulic Data, $6^{\text {th }}$ Edition, Ingersoll-Rand, Woodcliff Lake, New Jersey. 